\title{
Weight control belief and its impact on the effectiveness of tobacco control policies on quit attempts: findings from the ITC 4 Country Survey
}

\author{
Ce Shang, ${ }^{1}$ Frank J Chaloupka, ${ }^{1}, 2,3$ Geoffrey T Fong, ${ }^{4,5,6}$ Mary Thompson, ${ }^{7}$ \\ Mohammad Siahpush, ${ }^{8}$ William Ridgeway ${ }^{2}$
}

- Additional material is published online only. To view please visit the journal online (http://dx.doi.org/10.1136/ tobaccocontrol-2014-051886).

${ }^{1}$ Health Policy Center, Institute for Health Research and Policy, University of Illinois at

Chicago, Chicago, Illinois, USA ${ }^{2}$ Department of Economics, University of Illinois at Chicago, Chicago, Illinois, USA ${ }^{3}$ WHO Collaborating Centre on the Economics of Tobacco and Tobacco Control ${ }^{4}$ Department of Psychology, University of Waterloo, Waterloo, Canada ${ }^{5}$ Ontario Institute for Cancer Research, Toronto, Ontario, Canada

${ }^{6}$ School of Public Health and Health Systems, University of Waterloo, Ontario, Canada ${ }^{7}$ Department of Statistics and Actuarial Science, University of Waterloo, Waterloo, Ontario, Canada

${ }^{8}$ College of Public Health, University of Nebraska Medical Center, Omaha, Nebraska, USA

\section{Correspondence to}

Dr Ce Shang, Visiting Senior Research Specialist, Health

Policy Center, Institute for Health Research and Policy, University of Illinois at Chicago, 1747 W. Roosevelt Rd, Chicago, IL 60608, USA cshang@uic.edu.

Received 9 July 2014 Accepted 7 January 2015 Published Online First 2 February 2015

\section{CrossMark}

\section{To cite: Shang $C$,} Chaloupka FJ, Fong GT, et al. Tob Control 2015;24 iii41-iii47.

\section{ABSTRACT}

Background Weight concerns are widely documented as one of the major barriers for girls and young adult women to quit smoking. Therefore, it is important to investigate whether smokers who have weight concerns respond to tobacco control policies differently than smokers who do not in terms of quit attempts, and how this difference varies by gender and country.

Objective This study aims to investigate, by gender and country, whether smokers who believe that smoking helps control weight are less responsive to tobacco control policies with regards to quit attempts than those who do not.

Methods We use longitudinal data from the International Tobacco Control Policy Evaluation Project in the USA, Canada, the UK and Australia to conduct the analysis. We first constructed a dichotomous indicator for smokers who have the weight control belief and then examined the disparity in policy responsiveness in terms of quit attempts by directly estimating the interaction terms of policies and the weight control belief indicator using generalised estimating equations.

Findings We find that weight control belief significantly attenuates the policy impact of tobacco control measures on quit attempts among US female smokers and among UK smokers. This pattern was not found among smokers in Canada and Australia.

Conclusions Although our results vary by gender and country, the findings suggest that weight concerns do alter policy responsiveness in quit attempts in certain populations. Policy makers should take this into account and alleviate weight concerns to enhance the effectiveness of existing tobacco control policies on promoting quitting smoking.

\section{INTRODUCTION}

Weight-related concerns such as weight gain after quitting have been shown to discourage quitting and quit attempts among smokers. ${ }^{1-5}$ Nevertheless, the health benefits of quitting remain substantial even after taking account of the adverse health impact of the postcessation weight gain. ${ }^{6}$ In addition, for those smokers who use smoking as a weight control method, it may not be an efficient tool to control weight. $^{7}$ Existing studies indicate that heavy smokers, compared with light smokers, tend to be heavier, and ever-smokers, compared with neversmokers, do not experience less weight gain over time. ${ }^{8}$ Moreover, smoking is found to be associated with less physical activity and unhealthy diets that may in fact contribute to a weight gain..$^{9-11}$ Despite lack of scientific evidence that smoking is an effective weight control method, it is often regarded as a means of losing weight. Using US data, Cawley et $a l^{12}{ }^{13}$ found that weight gain is significantly associated with smoking initiation among girls, and $46 \%$ of girls and $30 \%$ of boys who are currently smoking, use cigarettes to control weight. ${ }^{14}$

While it is important to inform the public that smoking as a weight control method is indeed ineffective, little is known about whether weight concerns may attenuate the effectiveness of tobacco control policies in reducing smoking, ${ }^{15-21}$ that is, whether it results in an insignificant or reduced impact among population groups who have these concerns. Some indirect evidence suggests that they do; a high prevalence of weight concerns and low responsiveness to tobacco control policies often are observed together in certain populations. ${ }^{22-28}$ Studies using US data show that while weight concerns are higher among females than among males, ${ }^{1-3} 5141529$ the price impact on smoking is either insignificant or lower for females than for males. ${ }^{23}{ }^{25-27}$ US girls have also been found unresponsive to rising cigarette prices and are more likely to initiate smoking once experiencing a weight gain. ${ }^{12}$ Similar patterns are also found in racial comparisons. Compared with minority groups such as African Americans, Caucasians in the USA are more likely to report using cigarettes for weight control and are less price responsive. ${ }^{14} 22-2529$ In addition to the above evidence, Shang et al ${ }^{15}$ investigated the impact of the belief that smoking helps control weight on smokers' price responsiveness to reduce cigarette consumption and found that female smokers in the USA who hold such a belief are less price responsive than those who do not.

In all, very little evidence exists for the role of weight concerns in people's response to tobacco control policies. Although studies indicate that weight concerns inhibit quit attempts, it remains unclear whether weight concerns lower quit attempts through lowering smokers' response to tobacco control policies such as increasing cigarette prices. Therefore, it is important to extend the research to examine such mechanisms and elucidate whether policies that address weight concerns are needed to improve the effectiveness of other tobacco control policies. In this study, we employ the International Tobacco Control Policy Evaluation Project (ITC Project) data from the USA, the UK, Canada and Australia (ITC-4 country) to investigate the interaction effect of weight control belief and a variety of tobacco control policies (cigarette prices, antismoking 
messaging, worksite smoking bans, bar/pub smoking bans and restaurant smoking bans) on quit attempts. Based on the existing literature that show women are more likely to have weight concerns, ${ }^{1-3} 512-1529$ all analyses are conducted by gender.

\section{METHODS}

\section{Data}

The ITC Project conducts parallel longitudinal surveys of smokers and other tobacco users across 22 countries. The ITC surveys are designed to evaluate the policies of the WHO Framework Convention on Tobacco Control (Fong et $a l^{30}$ ) and their longitudinal properties allow us to follow smokers over years while observing their quitting and quit attempt behaviour since the initial wave. Compared with cross-sectional data, in the longitudinal data quit attempts are observed and less likely to contain measurement errors, and, when studying how tobacco control policies or cigarette prices are associated with quit attempts, longitudinal data allow a more precise match of locations where the policies are implemented to the smokers who are exposed to these policies.

We utilise ITC-4 country data waves 1-5 (2002-2007) that contain responses from smokers on their level of agreement with the statement that smoking helps control weight. The ITC Project also contains rich information on tobacco use-related factors including cigarette prices, exposure to tobacco control policies, and individual-level demographic characteristics that allow for testing the policy responsiveness by weight control belief while controlling for other factors.

In order to identify weight concerns related to smoking, we exploit a question that measures smokers' level of agreement with the following statement using a 5-point scale (strongly agree, agree, neither agree nor disagree, disagree and strongly disagree):

Smoking helps weight control.

The answers are employed to construct a dichotomous measure of the belief by coding those who answered strongly agree or agree with 1 and the rest with 0 . This indicator explicitly shows if a smoker may use smoking as a potential means to control weight, regardless of his or her actual body weight or body image. ${ }^{12} 31$ We consider this indicator to be a rudimentary measure of smoking-related weight concerns.

Table 1 contains the description and definition of weight control belief indicator, policy measures, and other correlates that are estimated in our analyses. The baseline period to start tracking quit attempt behaviour is the first wave of the survey when all participants were smoking. Thus the analysed sample consists of the second and later waves of each country. Smokers who have made a quit attempt since the last survey were assigned a value of 1 and smokers who have not were assigned a value of 0 . This quit attempt indicator is also equivalent to the percentage of smokers who quit or ever tried to quit since the last survey. The individual characteristic confounders that are controlled include respondents' age in the survey year (in linear and quadratic forms), marital status, employment status, education (indicators for three categories: low, middle and high education levels) and income (indicators for three categories: low, middle, high income levels). Respondents with missing education, income or employment status were dropped from the sample.

The ITC surveys asked respondents to report their recent exposure to tobacco control policies. The last purchase information of cigarettes such as the unit of cigarettes and the price per unit (per stick, pack or carton) was also asked. These selfreported measures of tobacco prices and control policies are crucial determinants of smoking behaviours yet highly correlated with individual unobserved heterogeneity in such behaviours. For example, heavy smokers are more likely to purchase cheaper cigarettes and thereafter report lower cigarette prices. They may be more likely to notice tobacco advertisements and report more such exposure as well. As a result, instead of directly using these self-reported measures in our analyses, we aggregated them at the stratum level where strata correspond to

\section{Table 1 Variable description and definition}

\begin{tabular}{|c|c|}
\hline Variable name & Description \\
\hline \multicolumn{2}{|l|}{ Individual level } \\
\hline Quit attempts & A dichotomous indicator equals 1 is the respondent has attempted to quit since the last wave, 0 otherwise \\
\hline $\begin{array}{l}\text { Weight control } \\
\text { belief=1 }\end{array}$ & $\begin{array}{l}\text { A dichotomous indicator equals } 1 \text { is the respondent strongly agrees or agrees on the weight control effect of smoking in the last wave, } \\
0 \text { otherwise }\end{array}$ \\
\hline Age & Age at the survey year \\
\hline Married & A dichotomous indicator equals 1 is the respondent is married, 0 otherwise \\
\hline Employed & A dichotomous indicator equals 1 is the respondent is employed, 0 otherwise \\
\hline Education & $\begin{array}{l}\text { Binary indicators for } 3 \text { categories: low, middle and high education (for the USA, Canada and Australia, these categories refer to high school or } \\
\text { less, community college/technical school or some college, and college and above; for the UK, these categories refer to secondary school, some } \\
\text { college, and college or above) }\end{array}$ \\
\hline Income & $\begin{array}{l}\text { Binary indicators for } 3 \text { categories: low, middle and high income (for the USA, Canada and Australia, these categories refer to annual household } \\
\text { income less than } \$ 30000, \$ 30000-59999 \text { and } \$ 60000 \text { or above; for the UK, these categories refer to annual household income at } f 15000 \text { or } \\
\text { lower, } f 15001-30000 \text { and } £ 30001 \text { or higher) }\end{array}$ \\
\hline \multicolumn{2}{|l|}{ Stratum level } \\
\hline Price & Stratum-specific cigarette prices for a pack of 20 cigarettes in constant 2010 dollars, constructed using the median price reported in each stratum \\
\hline Worksite bans & $\begin{array}{l}\text { The stratum level average of individuals' exposure to smoking restrictions at work place (1 no restriction, } 2 \text { some restriction, } 3 \text { full restriction); } \\
\text { possible range: } 1-3\end{array}$ \\
\hline Bar bans & $\begin{array}{l}\text { The stratum level average of individuals' exposure to smoking restrictions at bars (1 no restriction, } 2 \text { some restriction, } 3 \text { full restriction); possible } \\
\text { range: } 1-3\end{array}$ \\
\hline Restaurant bans & $\begin{array}{l}\text { The stratum level average of individuals' exposure to smoking restrictions at restaurants (1 no restriction, } 2 \text { some restriction, } 3 \text { full restriction); } \\
\text { possible range: } 1-3\end{array}$ \\
\hline $\begin{array}{l}\text { Antismoking } \\
\text { messaging }\end{array}$ & $\begin{array}{l}\text { Out of a number of antismoking broadcasting venues (TV, radio, etc), the fraction that each respondent was exposed to was calculated. } \\
\text { These individual fractions were averaged to the stratum level and rescaled by multiplying by } 10 \text {. Possible range: } 1-10\end{array}$ \\
\hline
\end{tabular}


regions in each of the countries. We analysed these stratum average measures, which are more likely to reflect market prices and, as a result, less likely to be endogenous. Thus, to obtain stratum cigarette prices, we first calculated individuals' selfreported cigarette prices for a pack of 20 cigarettes and constructed the stratum aggregated cigarette prices as the median value of prices that were reported by those who live in the stratum. We used aggregated median prices instead of mean prices because they are more robust to extreme values. ${ }^{32}$ These prices were then converted into 2010 constant international dollars using Purchasing-Power Parity (PPP) and Consumer Price Index (CPI) of the country. PPP conversion factor and CPI of each country were obtained from the International Monetary Fund World Economic Outlook database.

Likewise, individuals' exposures to worksite smoking bans, antismoking messaging, smoking restriction in bars and smoking restriction in restaurants were calculated and aggregated to stratum level mean index measures (details are presented in table 1). Specifically, in ITC surveys, respondents were asked to report their recent exposure to antismoking messaging in a list of venues (TV, radio, posters, etc). To develop an antismoking index, we first estimated, for each respondent, the fraction of venues at which the respondent has been exposed to, then aggregated these individual-level indices to the stratum level using mean indices, and rescaled the indices by multiplying them by 10 (the index ranges 1-10). The worksite, bar and restaurant indices were constructed at the stratum level using the mean of reported policy restriction levels in these locations (1 no restriction, 2 some restriction, 3 full restriction, indices range $1-3)$.

\section{Models}

In light of previous studies where significant gender disparity in weight concerns was found, and since tobacco control policies differ by countries, ${ }^{17}$ it is likely that the responses to tobacco control policies are manifested differently by gender and country. Hence, we stratified our analyses by gender and country in addition to carrying out analyses by pooling both genders. We restricted our studied sample to adult smokers aged 18-75. Our sample consists of smokers who smoked in the last wave and our dependent variable, the quit attempt indicator, measures smokers who actually quit since the last wave as well as smokers who attempted to quit but failed. In addition, given the high collinearity between stratum level tobacco control policies and wave fixed effects, we analysed each policy separately while controlling for other policies using a single mean measure constructed using the mean of all other policy indices (online supplementary appendix table 1 ).

Logistic regressions are used to directly test whether policy impacts vary by the weight control belief indicator for each tobacco control policy, respectively:

$$
\begin{aligned}
\operatorname{logit}\left(\text { Quit_Attempt }_{i t}\right)= & \beta_{0}+\beta_{1} \text { Policy }_{\mathrm{kt}} \times \mathrm{I}(\text { Belief }=1)_{i t-1} \\
& +\beta_{2} \text { Policy }_{\mathrm{kt}}+\beta_{3} \mathrm{I}(\text { Belief }=1)_{\mathrm{it}-1} \\
& +\beta_{4} \text { Other_Policy_Control }_{\mathrm{kt}}+\beta_{5} \mathrm{X}_{\mathrm{it}}
\end{aligned}
$$

where Quit_Attempt ${ }_{\text {it }}$ denotes the indicator of ever making a quit attempt since the last survey for person $i$ at wave $t$. Policy kt denotes one of the studied stratum-specific policies which are cigarette price, worksite smoking bans, bar smoking bans, restaurant smoking bans and antismoking messaging. Other_Policy_Control ${ }_{\mathrm{kt}}$ denotes the constructed single mean measure of all tobacco policies other than the Policy $\mathrm{kt}_{\text {. I }}$ (Belief $=1)_{\text {it-1 }}$ denotes the dichotomous measure of the weight control belief in the last survey. Following Cawley et $a l^{12}$ we use one lag of the belief indicator instead of the current one to reduce the potential reverse causality between quit attempts and weight control belief. This is because smokers who quit or attempted to quit may experience a postcessation weight gain and are more likely to agree that smoking helps weight control. Our main variable of interest is the interaction terms of the policy variables and the weight control belief indicator. A Wald test of the estimate of the interaction term provides a direct test of whether policy responsiveness differs by the weight control belief. $\mathrm{X}_{\mathrm{it}}$ is a vector of individual demographic characteristics including education (low education as the omitted category, middle and high education), income (low, middle, with high income as the omitted category), marital status, employment, age, a quadratic form of age and wave fixed effects. In the regressions using pooled samples of both genders, an indicator of being male is added to the model.

Given that the surveys for each country are longitudinal, to account for the correlation of the same individual over time, we use weighted generalised estimating equations (GEE) to estimate equation (1). Logistic link, a binomial family, and exchangeable working correlation are applied in estimating the method. ${ }^{33}$ GEE extends generalised linear models by adjusting for the correlated data, and yields consistent estimates even when the covariate structure is mis-specified. ${ }^{34}$ Additionally, the corresponding SEs are estimated using logistic regressions after accounting for the complicated survey designs of each ITC country. All analyses were conducted using Stata SE V.13.1.

\section{RESULTS}

We report weighted descriptive summary statistics of the quit attempt indicator and covariates by country and gender in table 2. These summary statistics are also adjusted for correlations between the same individuals over years. The results show that in the studied countries, quit attempt rates are $37-42 \%$ among male smokers and 39-42\% among female smokers. Consistent with the previous literature using the US data, we find that the prevalence of weight control belief among female smokers is about 10 percentage points higher than among male smokers. Namely, in the USA and Canada, weight control belief prevalence is $23 \%$ among male smokers and $38-39 \%$ among female smokers; in the UK, it is 28\% among male and $39 \%$ among female smokers; and in Australia, it is $25 \%$ among male and $32 \%$ among female smokers. The mean age of these smokers is about $42-43$ years. In addition, the stratum level policy variables are similar between genders within a country.

Further, in figure 1, we plot the attempt rates over years for each country and show that the quit attempt rates in the four countries are about $30-45 \%$.

Tables 3 shows the results from estimating equation (1). The estimates indicate that among US female smokers, weight control belief significantly alters their responsiveness to most studied tobacco control policies in terms of quit attempts. We find that weight control belief reduces price responsiveness among US female smokers $(\mathrm{p} \leq 0.1)$ and responsiveness to antismoking messaging $(\mathrm{p} \leq 0.01)$; in other words, increases in price and exposure to antismoking messaging lead to fewer quit attempts for those who have the weight control belief than for those who do not. More specifically, while a $10 \%$ increase in cigarette prices is associated with about $6 \%$ increase in quit attempts among female smokers who do not hold the weight control belief, the associations between prices and quit attempts 
Table 2 Weighted summary statistics for smokers aged 18-75, by gender

\begin{tabular}{|c|c|c|c|c|c|c|c|c|}
\hline & \multicolumn{2}{|l|}{ The USA } & \multicolumn{2}{|l|}{ Canada } & \multicolumn{2}{|l|}{ The UK } & \multicolumn{2}{|l|}{ Australia } \\
\hline & Male & Female & Male & Female & Male & Female & Male & Female \\
\hline Quit attempts & $0.37(0.02)$ & $0.41(0.01)$ & $0.42(0.01)$ & $0.42(0.01)$ & $0.37(0.01)$ & $0.39(0.01)$ & $0.40(0.01)$ & $0.42(0.01)$ \\
\hline Weight control Belief=1 & $0.23(0.01)$ & $0.38^{*}(0.01)$ & $0.23(0.01)$ & $0.39^{*}(0.01)$ & $0.28(0.01)$ & $0.39^{*}(0.01)$ & $0.25(0.01)$ & $0.32 *(0.01)$ \\
\hline Age & $42.35(0.46)$ & $43.19(0.40)$ & $42.33(0.44)$ & $43.06(0.40)$ & $43.11(0.49)$ & $43.27(0.51)$ & $41.62(0.46)$ & $40.96(0.40)$ \\
\hline Married & $0.33(0.02)$ & $0.33(0.01)$ & $0.27(0.01)$ & $0.28(0.01)$ & $0.31(0.01)$ & $0.27^{*}(0.01)$ & $0.28(0.01)$ & $0.27(0.01)$ \\
\hline Employed & $0.74(0.01)$ & $0.62^{*}(0.01)$ & $0.78(0.01)$ & $0.67^{*}(0.01)$ & $0.78(0.01)$ & $0.62^{*}(0.01)$ & $0.77(0.01)$ & $0.61 *(0.01)$ \\
\hline \multicolumn{9}{|l|}{ Education } \\
\hline Low & $0.10(0.01)$ & $0.09(0.01)$ & $0.14(0.01)$ & $0.15(0.01)$ & $0.31(0.02)$ & $0.36^{*}(0.02)$ & $0.38(0.02)$ & $0.40(0.01)$ \\
\hline Middle & $0.31(0.02)$ & $0.33(0.01)$ & $0.31(0.02)$ & $0.30(0.01)$ & $0.27(0.02)$ & $0.26(0.01)$ & $0.24(0.01)$ & $0.26(0.01)$ \\
\hline High & $0.60(0.02)$ & $0.58(0.02)$ & $0.55(0.02)$ & $0.56(0.01)$ & $0.42(0.02)$ & $0.39(0.02)$ & $0.38(0.02)$ & $0.35(0.01)$ \\
\hline \multicolumn{9}{|l|}{ Income } \\
\hline Low & $0.32(0.02)$ & $0.42^{*}(0.01)$ & $0.24(0.01)$ & $0.34^{*}(0.01)$ & $0.21(0.01)$ & $0.37^{*}(0.02)$ & $0.23(0.01)$ & $0.32^{*}(0.01)$ \\
\hline Middle & $0.39(0.02)$ & $0.38(0.01)$ & $0.40(0.02)$ & $0.37(0.01)$ & $0.36(0.02)$ & $0.37(0.02)$ & $0.36(0.01)$ & $0.35(0.01)$ \\
\hline High & $0.29(0.02)$ & $0.21 *(0.01)$ & $0.36(0.02)$ & $0.30 *(0.01)$ & $0.43(0.02)$ & $0.26^{*}(0.01)$ & $0.42(0.02)$ & $0.33^{*}(0.01)$ \\
\hline \multicolumn{9}{|l|}{ Stratum level policy } \\
\hline Price & $3.68(0.03)$ & $3.64(0.02)$ & $6.04(0.03)$ & $6.01(0.02)$ & $7.36(0.01)$ & $7.36(0.01)$ & $6.02(0.01)$ & $6.01(0.01)$ \\
\hline Worksite bans & $2.49(0.01)$ & $2.47^{*}(0.00)$ & $2.49(0.01)$ & $2.50(0.00)$ & $2.28(0.00)$ & $2.28(0.00)$ & $2.51(0.00)$ & $2.53(0.00)$ \\
\hline Bar bans & $2.04(0.01)$ & $1.99 *(0.01)$ & $2.29(0.01)$ & $2.30(0.01)$ & $1.73(0.00)$ & $1.72(0.00)$ & $2.09(0.00)$ & $2.10(0.00)$ \\
\hline Restaurant bans & $2.43(0.01)$ & $2.39^{*}(0.01)$ & $2.55(0.01)$ & $2.56(0.01)$ & $2.12(0.00)$ & $2.11(0.00)$ & $2.68(0.00)$ & $2.69(0.00)$ \\
\hline Antismoking messaging & $4.19(0.01)$ & $4.19(0.01)$ & $4.57^{*}(0.01)$ & $4.59(0.01)$ & $4.30(0.01)$ & $4.29(0.01)$ & $4.72(0.01)$ & $4.74 *(0.01)$ \\
\hline $\mathrm{N}$ & 1786 & 2480 & 2216 & 2844 & 2194 & 2805 & 2453 & 2998 \\
\hline
\end{tabular}

are insignificant among smokers who have such a belief. Similarly, while a $10 \%$ increase in the exposure to antismoking messaging is associated with a $12 \%$ increase in quit attempts among female smokers who do not have weight control belief, it is not associated with an increase in quit attempts among those who do have such a belief. In addition, although exposure to more restrictive bar and restaurant tobacco control policies is positively but not significantly associated with quit attempts among US female smokers who do not have the belief, the interaction term of weight control belief and these policies are significantly negative. We do not see any patterns for men.

Table 3 also shows that in Canada and Australia weight control belief does not seem to alter policy responsiveness. In the UK, while a $10 \%$ increase in exposure to antismoking messaging is significantly associated with a $13 \%$ increase in quit attempts in the pooled sample of male and female smokers, weight control belief significantly reduces the responsiveness to

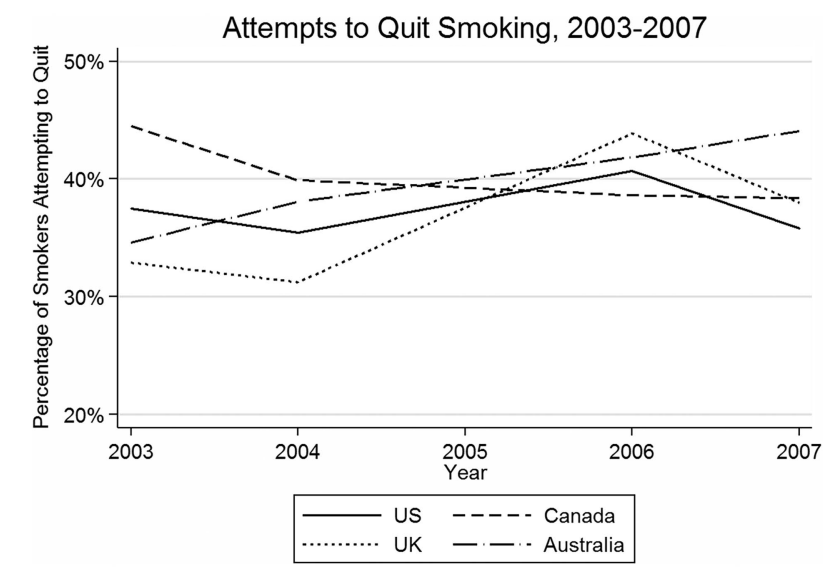

Figure 1 Quit Attempts in the USA, the UK, Canada, and Australia. antismoking messaging in the sense that smokers who have such a belief are not responsive to antismoking messaging. Although exposure to worksite smoking bans and increasing prices are positively but not significantly associated with quit attempts among UK smokers who do not have the belief, the interaction term of weight control belief and these policies are significantly negative.

In all, the results presented above suggest very different policy responsiveness by the weight control belief among US female smokers and among UK smokers. We do not find positive and significant associations between some tobacco control policies and quit attempts in some countries, which is likely due to the lack of subnational policies or policy change during the study period. Nevertheless, our results pertaining to the US female smokers illustrate that there is a heterogeneity in policy responsiveness between those who have the weight control belief and those who do not. Therefore, weight concerns may contribute to the lack of responsiveness among US female smokers found in the existing literature. This is also consistent with a recent finding which suggests that US female smokers with weight control belief tend to be less price responsive in reducing cigarette consumption than those without the belief as price increases. $^{15}$

\section{CONCLUSIONS}

This study marks the first effort to answer whether weight concerns alter smokers' responsiveness to tobacco control policies in making a quit attempt. Using data taken from the ITC 4 country project we analysed the policy impact by allowing it to differ by whether the smoker agrees that smoking helps weight control. We find that weight control belief significantly attenuates policy impacts on promoting quit attempts among US female smokers. Our findings in part explain why many previous studies have found that female US smokers do not seem to 
Table 3 The associations between tobacco control policies and quit attempts by country, gender and weight control belief

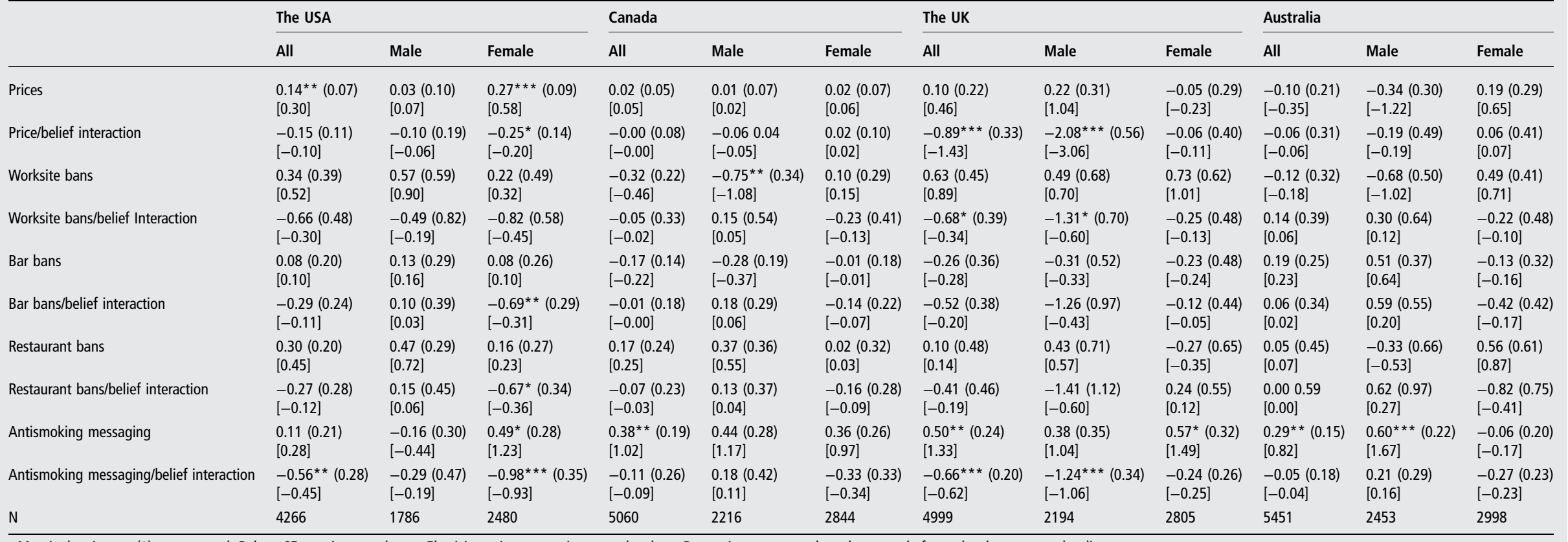

Marginal estimates ( $\beta$ ) are reported. Robust SEs are in parentheses. Elasticity estimates are in square brackets. Regressions were conducted separately for each tobacco control policy. ${ }^{*} 0.05<p \leq 0.1,{ }^{* *} 0.01<p \leq 0.05,{ }^{* * *} p \leq 0.01$. 
respond to price increases by reducing their smoking participation. In other words, weight concerns do moderate these smokers' responsiveness to tobacco control policies to discourage quit attempts and keep them continuing to smoke. Similar patterns are also found in pooled samples of UK female and male smokers, but not among smokers in Australia and Canada.

We acknowledge that there are some limitations to this study. First, we constructed our weight control belief measure using self-reported answers which may contain some measurement errors and errors from respondents who reported 'neither agree nor disagree'. However, we conducted some sensitivity analyses by categorising 'neither agree nor disagree' as having the weight control belief and most of results remain similar. Second, our weight control belief measure is not specific enough to answer whether it is a concern of postcessation weight gain or other weight-related concerns and respondents' weights or BMIs are not available in the data. Third, for most countries there is not enough variation in policy measures that can be employed to identify policy impacts. Therefore, although most of our policy estimates are positive, they are not significant. Nevertheless, we were still able to detect some difference in the policy impact by weight control belief among US female smokers and UK smokers. Fourth, since we only have four waves of data and ITC is a longitudinal survey, there is not sufficient variation of quitting over time for us to examine the interaction effect of weight concerns and policy responsiveness by quitting.

Despite these limitations, our findings provide important empirical evidence that the efficacy of tobacco control policies in certain subpopulations may be greatly reduced by some unobserved smoking-related factors such as weight concerns. The insignificant or small price impact on female smokers in the USA, to some extent, can be attributed to weight concerns that are very prevalent among females. Identifying these potential factors is crucial to improving the effectiveness of tobacco control policies in certain subpopulations. Since we found that weight concerns do in fact attenuate policy responsiveness in certain populations, policy makers should take this into account and alleviate weight concerns to enhance the effectiveness of existing tobacco control policies on promoting quit attempts and reducing smoking.

\section{What this paper adds}

- This paper provides the first analysis on whether weight concerns alter smokers' responsiveness to tobacco control policies in making a quit attempt.

- Among US female smokers and UK smokers, weight concerns do moderate smokers' responsiveness to tobacco control policies to discourage quit attempts and keep them continuing to smoke.

Acknowledgements The authors would like to thank the ITC Principal Investigators of the USA (K. Michael Cummings and Andrew Hyland), the UK (Gerard Hasting and Ann McNeill), Canada (Geoffrey T. Fong), Australia (Ron Borland). They would like to acknowledge all country team members.

Contributors CS, FJC, GTF, MT, and MS planned the work described in the article. CS and WR conducted the analyses, wrote the draft and reported the work after discussion with other authors. CS is responsible for the overall content as guarantor.

Funding The data collection for the ITC Project is supported by grants R01 CA 100362 and P50 CA111236 (Roswell Park Transdisciplinary Tobacco Use Research Center, and P01 CA138389, R01 CA090955) from the National Cancer Institute of the USA, Robert Wood Johnson Foundation (045734), Canadian Institutes of Health
Research (57897, 79551, and 115016), Commonwealth Department of Health and Aging, Canadian Tobacco Control Research Initiative (014578), National Health and Medical Research Council of Australia (265903), Cancer Research UK (C312/A3726, C312/A6465, C321/A11039, C312/A11943). Additional support was provided to Geoffrey T. Fong from a Senior Investigator Award from the Ontario Institute for Cancer Research and a Prevention Scientist Award from the Canadian Cancer Society Research Institute.

Competing interests None declared.

\section{Patient consent Obtained.}

Ethics approval All ITC Surveys were conducted with the approval of the Office of Research Ethics Committee at the University of Waterloo, Canada and the respective Internal Review Boards for each country.

Provenance and peer review Not commissioned; externally peer reviewed.

\section{REFERENCES}

1 Borrelli B, Mermelstein R. The role of weight concern and self-efficacy in smoking cessation and weight gain among smokers in a clinic-based cessation program. Addict Behav 1998;23:609-22.

2 Pisinger $C$, Jorgensen T. Weight concerns and smoking in a general population: the Inter99 study. Prev Med 2007;44:283-9.

3 Pomerleau CS, Zucker AN, Stewart AJ. Characterizing concerns about post-cessation weight gain: results from a national survey of women smokers. Nicotine Tob Res 2001;3:51-60.

4 Mukhopadhyay $S$, Wendal J. Is post-smoking-cessation weight-gain a significant trigger for relapse? App/ Econ 2011;43:3449-57.

5 Aubin H, Berlin I, Smadja E, et al. Factors associated with higher body mass index, weight concern and weight gain in a multinational cohort study of smokers intending to quit. Int J Environ Res Public Health 2009;6:943-57.

6 Siahpush M, Singh GK, Tibbits $M$, et al. It is better to be a fat ex-smoker than a thin smoker: findings from the 1997-2004 National Health Interview Survey-National Death Index linkage study. Tob Control 2014;23:395-402.

7 Chiolero A, Faeh D, Paccand F, et al. Consequences of smoking for body weight, body fat distribution and insulin resistance. Am J Clin Nutr 2008;87:801-9.

8 John U, Hanke M, Rumpf HJ, et al. Smoking status, cigarettes per day, and their relationship to overweight and obesity among former and current smokers in a national adult general population sample. Int J Obesity (Lond) 2005;29:1289-94.

9 Thompson RL, Margetts BM, Wood DA, et al. Cigarette smoking and food and nutrient intakes in relation to coronary heart disease. Nutr Res Rev 1992;5:131-2.

10 Serdula MK, Byers T, Mokdad AH, et al. The association between fruit and vegetable intake and chronic disease risk factors. Epidemiology 1996;7:161-5.

11 Kvaavik E, Meyer HE, Tverdal A. Food habits, physical activity and body mass index in relation to smoking status in 40-42 year old Norwegian women and men. Prev Med 2004;38:1-5.

12 Cawley J, Markowitz S, Tauras J. Lighting up and slimming down: the effects of body weight and cigarette prices on adolescent smoking initiation. $J$ Health Econ 2004;23:293-311.

13 Cawley J, Markowitz S, Tauras J. Body weight, cigarette prices, youth access laws and adolescent smoking initiation. East Econ J 2006;32:149-70.

14 Cawley J, Scholder SV. The demand for cigarettes as derived from the demand for weight control. NBER Working Paper No. 18805 2013. doi:10.3386/w18805

15 Shang C, Chaloupka FJ, Fong GT, et al. The impact of weight control belief on cigarette consumption among adults: findings from the ITC Project. Philadelphia, PA: American Economic Association, 2013.

16 Chaloupka FJ, Warner KE. The economics of smoking. In: Culyer AJ, Newhouse JP, eds. Handbook of health economics. Amsterdam, North Holland: Elsevier B.V., 2000:1539-627.

17 International Agency for Research on Cancer. IARC Handbooks of Cancer Prevention, Tobacco Control. Vol. 14: Effectiveness of Tax and Price Policies for Tobacco Control. Lyon, France: International Agency for Research on Cancer, 2011.

18 Kostova D. A (nearly) global look at the dynamics of youth smoking initiation and cessation: the role of cigarette prices. Appl Econ 2013;45:3943-51.

19 Kostova D, Chaloupka FJ, Shang C. A duration analysis of the role of cigarette prices on smoking initiation and cessation in developing countries. Eur $\mathrm{J}$ Health Econ 2014. Published Online First: 9 Mar 2014. doi:10.1007/s10198-014-0573-9.

20 Shang C, Chaloupka FJ, Guidon GE, et al. Smoking initiation and cessation in India-a duration analysis. Los Angeles, CA: American Society of Health Economists, 2014

21 Shang C, Chaloupka FJ, Kostova D. Who quits? An overview of quitters in low- and middle-income countries. Nicotine Tob Res 2014;16(Suppl 1):S44-55.

22 Tauras JA, Huang J, Chaloupka FJ. Differential impact of tobacco control policies on youth sub-populations. Int J Environ Res Public Health 2013;10:4306-22.

23 Chaloupka FJ, Pacula RL. Sex and race differences in young people's responsiveness to price and tobacco policies. Tob Control 1999;8:373-7.

24 Farrelly MC, Bray JW, Pechacek T, et al. Response by adults to increases in cigarette prices by sociodemographic characteristics. South Econ J 2001;68:156-65. 
25 Farrelly MC, Bray JW. Response to increases in cigarette prices by race/ethnicity, income, and age groups. MMWR Morb Mortal Wkly Rep 1998;47: 605-9.

26 Hersch J. Gender, income levels, and the demand for cigarettes. J Risk Uncertainty 2000;21:263-82.

27 Chaloupka FJ. Men, women, and addiction: the case of cigarette smoking. NBER Working Paper No. 32671990 Feb. doi:10.3386/w3267

28 Chaloupka FJ, Straif K, Leon ME. Effectiveness of tax and price policies in tobacco control. Tob Control 2011;20:235-8.

29 Sanchez-Johnsen LA, Carpentier MR, King AC. Race and sex associations to weight concerns among urban African Americans and Caucasian smokers. Addict Behav 2011;36:14-17.
30 Fong GT, Cummings KM, Borland R, et al. The conceptual framework of the International Tobacco Control (ITC) policy evaluation project. Tob Control 2006;15 (Suppl 3):iii3-11.

31 Twardella $D$, Loew $M$, Rothenbacher $D$, et al. The impact of body weight on smoking cessation in German adults. Prev Med 2006;42:109-13.

32 Shang C, Chaloupka FJ, Zahra N, et al. The distribution of cigarette prices under different tax structures: findings from the International Tobacco Control Policy Evaluation (ITC) project. Tob Control 2014;23(Suppl 1):i23-9.

33 Hedeker D, Gibbons RD. Longitudinal data analysis. Hoboken, NY: John Wiley \& Sons, Inc., 2006:131-46. ISBN:978-0-471-42027-9.

34 Zegar SL, Liang KY, Albert PS. Models for longitudinal data: a generalized estimating equation approach. Biometrics 1988;44:1049-60. 